\title{
Inaccuracies in Phytic Acid Measurement: Implications for Mineral Biofortification and Bioavailability
}

\author{
Pushparajah Thavarajah", Dil Thavarajah \\ School of Food Systems, North Dakota State University, Fargo, USA. \\ Email: ${ }^{*}$ pushparajah.thavaraj@ndsu.edu
}

Received August 27 ${ }^{\text {th }}$ 2013; revised November $6^{\text {th }}$, 2013; accepted December $18^{\text {th }}, 2013$

Copyright (C) 2014 Pushparajah Thavarajah, Dil Thavarajah. This is an open access article distributed under the Creative Commons Attribution License, which permits unrestricted use, distribution, and reproduction in any medium, provided the original work is properly cited. In accordance of the Creative Commons Attribution License all Copyrights (C) 2014 are reserved for SCIRP and the owner of the intellectual property Pushparajah Thavarajah, Dil Thavarajah. All Copyright (C) 2014 are guarded by law and by SCIRP as a guardian.

\section{ABSTRACT}

Biofortification of commonly eaten staple food crops with essential mineral micronutrients is a potential sustainable solution to global micronutrient malnutrition. Because phytic acid (PA; 1,2,3,4,5,6-hexakis myo-inositol) reduces mineral micronutrient bioavailability, reduction of $P A$ levels could increase the bioavailability of biofortified iron (Fe), zinc ( $\mathrm{Zn})$, calcium (Ca), and magnesium (Mg). PA is viewed as an anti-nutrient, yet PA and other inositol phosphates have also demonstrated positive health benefits. Phytic acid analysis in the agricultural, food, and nutritional sciences is typically carried out by colorimetry and chromatographic techniques. In addition, advanced techniques such as nuclear magnetic resonance and synchrotron $\mathrm{X}$-ray absorption spectroscopy have also been used in phytic acid analysis. The colorimetric analysis may overestimate PA levels and synchrotron $\mathrm{X}$-ray absorption techniques may not detect very low levels of inositol phosphates. This short communication discusses the advantages and disadvantages of each widely used phytic acid analysis method, and suggests high performance anion exchange (HPAE) chromatography with conductivity detection (CD) based analysis can achieve greater accuracy for the identification and quantification of inositol phosphates. Accurate characterization and quantification of PA and inositol phosphates will inform PA reduction and biofortification efforts, allowing retention of the benefits of non-phytic inositol phosphates for both plants and humans.

\section{KEYWORDS}

Biofortification; Bioavailability; Phytic Acid; Inositol Phosphate; Chemical Analysis; Quantification; Analytical Errors; Diet; Health

\section{Introduction}

Phytic acid (PA; 1,2,3,4,5,6-hexakis myo-inositol), an inositol phosphate isomer, is considered as an anti-nutrient in food, agriculture, and nutritional sciences. The role of PA as a food anti-nutrient motivated research aimed at reducing the PA content of commonly eaten foods through food processing, genetic engineering, and plant breeding. For example, processing and fermentation during bread making, malting, and blanching can result in significant PA reduction [1-4]. Phytic acid and its salts are present at $0.5 \%$ to $5 \%(\mathrm{w} / \mathrm{w})$ levels in edible legumes, cereal grains, oilseeds and nuts [5-8]. Genetic

${ }^{*}$ Corresponding author. engineering and plant breeding efforts to reduce PA have resulted in the development of low PA (0.52 to 4.56 $\mathrm{mg} / \mathrm{g}$ of phytic acid phosphorous) mutants in major cereal crops, such as maize (Zea mays L.), rice (Oryza sativa L.), wheat (Triticum aestivum L.), common bean (Phaseolus vulgaris L.), and barley (Hordeum vulgare L.) [9-12]. Animal studies have shown that substantial reductions in phytic acid levels in feed lead to improvements in calcium (Ca) and zinc (Zn) utilization [13,14].

Although PA is typically viewed as a food anti-nutrient, recent inositol phosphate research shows PA and other inositol phosphates may provide a range of human health benefits. Moderate intakes of PA provide positive health effects for humans and several animal and epide- 
miological studies demonstrate beneficial effects of dietary PA, including decreased risk of heart disease, renal stone formation, and colon cancer [15]. Phytic acid may also be vital for plant health: efforts to reduce plant PA and other inositol phosphates may lower seed germination and plant health. Therefore, complete elimination of PA and other inositol phosphates might not be a good strategy, given their central roles in plant cellular and seed function and their positive health benefits for humans. Maintenance of moderate ( 1\%) PA and other inositol phosphate levels through appropriate food processing, cooking, and plant breeding might instead be aimed at achieving a balance between the positive and negative aspects of phytic acids.

The PA central role in plant and human health has led to the development of different PA analytical methods. Most studies quantified PA by using colorimetric procedures as total phosphorus (P) or after separation of $\mathrm{P}$ into organic and inorganic bound forms [16]. However, the accuracy of colorimetric PA assays depends on the separation of different inositol isomers, assumptions of metal-color complexes, and chemical matrix interferences [17]. The colorimetry-based PA-P determination has been the method of choice for reporting the PA content of rice [10], field pea [18], wheat [9], soybean [12], maize [8], and common bean [19]. Therefore, the accuracy of the PA levels reported in these and many other studies is subject to the errors associated with the colorimetric procedures. Recently, high performance liquid chromatography (HPLC) based PA analytical methods have become popular for PA analysis method due to higher analytical accuracies and high throughput capabilities. Synchrotron X-ray based and nuclear magnetic resonance spectroscopy based methods also have been used in PA analysis in a limited number of studies.

The objectives of this review are to discuss 1 ) the role of PA in major staple food crops and in human health; 2) analytical errors with most commonly used methods to quantify PA and other inositol phosphates; and 3) discuss the importance of analytical accuracy in the context of global mineral micronutrient biofortification/bioavailability efforts.

\section{Biology of Phytates in Plants}

Seeds store $\mathrm{P}$ as organic phosphates (e.g., bound to inositol) or inorganic phosphates (e.g., sodium $(\mathrm{Na})$, potassium $(\mathrm{K})$, calcium $(\mathrm{Ca})$, magnesium $(\mathrm{Mg})$, iron $(\mathrm{Fe})$ and zinc (Zn) phosphates). Inositol can exist as nine possible isomers [20], with any or all of the hydroxyl groups esterified with phosphates. Although 63 inositol isomers with bound phosphate are possible, based on myoinositol hydroxyl groups in axial and equatorial positions, only 15 different inositol phosphates have been identified in plant and animal tissues [21]. Inositol hexaphosphate
(IP6) or PA is the most abundant inositol phosphate; however, significant quantities of other inositol phosphates have been reported in cereals, pulses, and oil seeds. All inositol phosphates, including PA, are collectively known as phytates.

Phytic acid metabolism in plants has been extensively reviewed [22]. Phytic acid biosynthesis begins with inositol (Ins) synthesis followed by glucose-6-phosphate conversion to Ins(1)P and a dephosphorylation step to myo-inositol. Myo-inositol is a central plant metabolic constituent for several biochemical pathways, including indole-3-acetic acid (IAA) metabolism, cell-wall polysaccharide and cyclitol synthesis, signal and energy transduction, regulation, and ATP generation. Sequential phosphorylation of myo-inositol by inositol phosphate, polyphosphate kinases, and phosphotransferases results in PA [23]. PA is a major constituent in Ins $\mathrm{P}$ and pyrophosphate (PP) pathways, participating in signal transduction [24], and ATP regeneration [24], serving as a ligand, playing a role in RNA export, DNA repair, DNA recombination [25], and endocytosis and vesicular trafficking [26], as well as serving as an antioxidant [27,28]. The non-PA Ins $\mathrm{P}$ compound, 5-PP-Ins $(1,3,4,6) \mathrm{P}_{4}$, is similar to PA and contains 6 moles of $\mathrm{P}$ per mole of Ins [22]. Among the other phosphorylated derivatives, 5pyrophosphate-Ins $(1,2,3,4,6)-5$-phosphate [5-PP-Ins (1, $2,3,4,6) \mathrm{P}_{5}$ ] contains 7 moles of $\mathrm{P}$ per mole of inositol and 5,6-bis pyrophosphate-Ins (1,2,3,4)-4-phosphate [5-PPIns $\left.(1,2,3,4) \mathrm{P}_{4}\right]$ contains 8 moles of $\mathrm{P}$ per mole of inositol. These highly phosphorylated PP derivatives serve in a number of physiological functions and processes in plant cells beyond simple P storage [22].

Phytic acid accounts for $0.5 \%$ - $5 \%$ by weight of cereals, pulses, tubers, fruits, and vegetables. PA accumulates during seed development and is utilized during germination to maintain a relatively constant level of inorganic P. The primary functions of PA in the seed are to 1) provide storage for cations and P; 2) act as a precursor for cell wall development; 3) act as a storehouse for potential energy; 4) enable cell signaling, and 5) provide antioxidant protection against free radicals and iron. Approximately $60 \%$ - $90 \%$ of the total seed $\mathrm{P}$ is a mixture of $\mathrm{Ca}, \mathrm{Mg}$, and $\mathrm{K}$ salts as a crystalloid-type substructure (globoids) of protein present in the aleurone layer and germ. Wheat and rice have higher concentrations of PA in the aleurone layer while corn has a high concentration of PA in the germ [28]. In legumes, PA is mostly found in the embryo axis [29]; its concentration varies among species, with whole lentil seeds naturally low in PA compared to other pulses [29-31].

Phytic acid provides numerous benefits to both plant seeds and human health. The seeds of some plants species can remain viable for more than 400 years [32]. The reason for this long-term survival is unclear, but these 
seeds contain large amounts of highly unsaturated lipids, $\mathrm{Fe}$, and natural antioxidants such as alpha-tocopherol, phenols, and PA. Among these, PA acts as an antioxidant by chelating $\mathrm{Fe}$ in the $\mathrm{Fe}^{3+}$ oxidation state and preventing the generation of peroxides and other activated oxygen species. In foods, PA inhibits lipid peroxidation, oxidative spoilage, discoloration, putrefaction, and syneresis. In addition, dietary PA acts as an antioxidant, cellular signal transducer, and an intermediate for cellular communications, thereby contributing to a lower the incidence of colonic cancer, inflammatory bowel disorder, and cardiovascular diseases in humans [28,33]. Overall, PA is clearly an important component in natural food systems. While PA reduction efforts are desirable for increasing the bioavailability of natural and biofortified minerals, and thus reduce micronutrient malnutrition, a balanced approach towards maintaining certain levels of PA and other inositol phosphates is important to preserve the benefits of these compounds. However, accurate identification and quantification of inositol phosphates with structural similarity to PA poses significant challenges.

\section{Phytic Acid Analysis}

Efforts to biofortify staple crops with essential mineral micronutrients, increase mineral bioavailability through PA reduction, and exploit positive health benefits of PA and other inositol phosphates, all require accurate analysis of target inositol phosphates.

\subsection{Extraction of Inositol Phosphates from Seeds and Plant Tissues}

Inositol phosphates are highly soluble in acidic conditions. Therefore, most PA and other phosphates from finely ground seed or plant materials can be efficiently extracted by boiling $\left(100^{\circ} \mathrm{C}\right)$ in acidic conditions $(0.5 \mathrm{M}$ $\mathrm{HCl})$ for 5 to 10 minutes. The extracted inositol phosphates can be further decomplexed from solubilized macromolecules by addition of stronger acid $(12 \mathrm{M} \mathrm{HCl})$. Acid-based extraction procedures have provided the highest extraction efficiencies of inositol phosphates from cereals, legumes, and other low fat food items $[29,34]$. High oil/fat samples may require defatting prior to PA extraction to reduce fat interferences in the PA extraction.

\subsection{Separation of PA from Inositol and Inorganic Phosphates}

Inositol phosphates can be separated by paper, thin-layer, column, and high-performance liquid chromatography techniques. Paper and thin-layer are inexpensive chromatographic techniques to separate various categories of phosphates. Column chromatography provides moderate resolution of different phosphates: it is also the most commonly used technique to separate inositol phosphates from inorganic phosphates. Because of its resolving power of different phosphate groups, simplicity and rapid sample analysis capability, this has been a method of PA analytical choice for recent plant breeding and biofortification activities. Although column chromatographic techniques only allow separation of different inositol and inorganic phosphate categories, it may not be a suitable technique to separate structurally similar inositol phosphates. They typically do not clearly separate PA from other inositol phosphates, and thus lead to overestimates in the PA values reported.

High-performance liquid chromatography (HPLC) provides chromatographic resolution of numerous inositol phosphate isomers and the necessary versatility to analyze individual phosphates [35,36]. High performance anion exchange (HPAE) chromatography has been used for decades to separate inositol isomers in chemistry, biochemistry, and medical research, and is now gaining greater acceptance for the analysis of PA and other inositol phosphates in food, nutritional and agricultural sciences. Reversed phase ion paired HPLC (RP-HPLC) has also been used in PA separation as this HPLC procedure for simultaneous separation of inositol phosphates [37]. However, HPAE is superior to RP-HPLC because it can separate inositol phosphates based on the number of phosphate groups, including different isomeric forms (except enantiomers). HPAE-based methods have been used to determine phytic acid levels in pulses, cereals, and barley [29,34]. HPAE-based inositol phosphate separation can provide rapid ( $10 \mathrm{~min})$ sample PA analysis capabilities. However, this method requires HPLC instrumentation as well as a moderate to high level of technical understanding of anion exchange chromatography and inositol phosphate chemistry. While this method cannot be adapted to all situations, it provides superior inositol phosphate data and the equipment investment may be recovered through efficient use of resources otherwise not available with other techniques.

\subsection{Identification and Quantification of PA and Other Inositol Phosphates}

Inositol phosphates, including PA, lack chromophores to absorb ultraviolet-visible (UV-Vis) light; therefore, identification and quantification is carried out by precipitation, color development, refractive index measurement, and conductivity detection methods. Precipitation and color development methods require PA and inositol phosphates to complex with a metal ion. Quantification of precipitated materials or solution color intensity change can be used as a measure of PA concentrations. Briefly, iron (Fe) in a solution of phytate can bind to the phosphate ester. Quantification of Fe or P in the precipitate 
indicates the amount of inositol phosphates. Quantification of free Fe with a ligand such as sulfosalicylic acid (reduction in pink color intensity) can also be used to measure inositol phosphates. However, this method is prone to analytical errors due to changing assumptions regarding the different molecular ratios within the inositol phosphate and iron complexes. In addition, the ability of organic acids and phenolic compounds to complex with Fe results in overestimation errors. However, colorimetric based methods are still popular and have been used due to their simplicity and low cost.

Variety of other inositol phosphate detection methods other than colorimetric procedures has also been used in detection of phosphates; however, conductivity, refractive index, nuclear magnetic resonance, derivatization of phosphates with UV-Vis/fluorescence active compounds, and X-ray fluorescence detection methods are main detection methods. The refractive index detection can have a lower sensitivity (below $1 \%$ levels) depending on the type of inositol phosphate. Conductivity based detection provide greater detection (at ppm levels) capabilities of phosphates. However, $\mathrm{H}^{+} / \mathrm{OH}^{-}$suppression under extreme acid and alkaline medium might be needed to improve phosphate detection and to improve sensitivities.

${ }^{31} \mathrm{P}$ nuclear magnetic resonance, infrared, and X-ray absorption spectroscopies have been used to analyze inositol phosphates in intact samples. However, they require high (\% levels) inositol phosphate concentrations and may lack spectroscopic resolution to separate structurally similar inositol phosphate isomers.

Conductivity detection (CD) is often paired with HPAE to quantify inositol isomers. The ability to separate complex mixtures of different inositol phosphate isomers and detect separated compounds based on conductivities makes HPAE-CD a superior method for accurate inositol isomer quantification. Other detection methods include UV-Vis and fluorescence detection after derivatizing inositol phosphates; however, errors associated with derivatization are of concern for accurate quantification. It has been found that other PA analytical measurement errors can be high as $27 \%$ compared to HPLC methods [34]. The inclusion of lower inositol phosphates (penta-, tetra- and triphosphates) may be factor in these methods overestimating levels of PA. ${ }^{31} \mathrm{P}$ nuclear magnetic resonance, infrared, and X-ray absorption spectroscopies have been used to analyze highly concentrated inositol phosphates in intact samples, and thus have no errors associated with sample preparation.

\section{Relevance to Biofortification and Bioavailability Research}

Approximately one-third of the world's population is deficient in essential mineral micronutrients $\mathrm{Fe}, \mathrm{Zn}, \mathrm{Ca}$ and $\mathrm{Mg}$. While enrichment of commonly eaten foods with essential micronutrients is seen as a sustainable solution to global micronutrient malnutrition, such efforts will have limited impact on the most vulnerable populations unless the biofortified minerals are highly bioavailable. Therefore, selection of low PA foods and finding ways to reduce PA through cooking and processing operations could greatly increase mineral bioavailability. All of these require accurate PA quantification.

Inaccurate identification and quantification of PA may also lead to undesired consequences: plant breeding and genetic engineering decisions that may change the profiles of other plant inositol phosphates. The inositol family phosphates do provide a central role to the plant's metabolic functions, survival, and seed germination potential. Therefore, accurate inositol phosphate identification and quantification is not only central to informing meaningful PA reduction efforts but also vital for developing healthy plants through plant breeding, genetic engineering, and agronomic efforts.

In summary, the HPAE-conductivity detection based inositol phosphate analytical procedures could provide accurate identification and quantification of PA and lack errors associated with colorimetric methods. Although ${ }^{31} \mathrm{P}$-NMR and synchrotron based methods could be used for intact sample inositol phosphate analysis, these methods might not provide chemical resolutions at very low $(<0.5 \%)$ sample concentration, besides prohibitive costs and technical skills required for routine analysis. Establishment of an accurate PA and other inositol phosphates analytical procedures could provide means to balance ways to reduce anti-nutrient effects phytic acid, and reap potential health benefits from inositol phosphate compounds for plant and human health.

\section{Highlights}

- Biofortification may be a sustainable food solution to micronutrient malnutrition;

- Accurate phytic acid analysis facilitate to improve mineral bioavailability efforts;

- HPAE-CD has fewer errors in phytic acid and inositol phosphate quantification.

\section{REFERENCES}

[1] N. R. Natubu and P. Markakis, "Effect of Fermentation Time on the Inositol Phosphates of Bread," Journal of Food Sciences, Vol. 48, No. 1, 1983, pp. 262-263. http://dx.doi.org/10.1111/j.1365-2621.1983.tb14841.x

[2] M. Larson and A. S. Sandberg, "Phytate Reduction in Bread Containing Oat Flour, Oat Bran or Rye Bran,” Journal of Cereal Science, Vol. 14, No. 2, 1991, pp. 141149. http://dx.doi.org/10.1016/S0733-5210(09)80135-5

[3] M. Brune, L. Rossander-Hulten, L. Hallberg, A. Gleerup and A. S. Sandberg, "Iron Absorption from Bread in $\mathrm{Hu}$ mans: Inhibiting Effects of Cereal Fiber, Phytate and In- 
ositol Phosphates with Different Numbers of Phosphate Groups,” The Journal of Nutrition, Vol. 122, 1992, pp. 442-449.

[4] S. S. Archana and A. Kawatra, "Reduction of Polyphenols and Phytic Acid Content of Pearl Miller Grains by Malting and Balancing," Plant Foods for Human Nutrition, Vol. 53, 1998, pp. 93-98. http://dx.doi.org/10.1023/A:1008060604880

[5] E. Graf and F. R. Dintzis, "Determination of Phytic Acid in Foods by High-Performance Liquid Chromatography," Journal of Agricultural and Food Chemistry, Vol. 30, No. 6, 1982, pp. 1094-1097. http://dx.doi.org/10.1021/jf00114a022

[6] F. Crea, C. De Stefano, D. Milea and S. Sammartano, "Formation and Stability of Phytate Complexes in Solution,” Coordination Chemistry Reviews, Vol. 252, 2008, pp. $1108-1120$. http://dx.doi.org/10.1016/j.ccr.2007.09.008

[7] V. Raboy, "Progress in Breeding Low Phytate Crops," Journal of Nutrition, Vol. 132, No. 3, 2002, pp. 503S$505 S$.

[8] R. Pilu, D. Panzeri, G. Gavazzi, S. K. Rasmussen, G. Consonni and E. Nielsen, "Phenotypic, Genetic and Molecular Characterization of a Maize Low Phytic Acid Mutant (lpa241)," Theoretical. Applied Genetics, Vol. 107, 2003, pp. 980-987.

http://dx.doi.org/10.1007/s00122-003-1316-y

[9] M. J. Guttieri, K. M. Peterson and E. J. Souza, “Agronomic Performance of Low Phytic Acid Wheat," Crop Science, Vol. 46, 2006, pp. 2623-2629. http://dx.doi.org/10.2135/cropsci2006.01.0008

[10] S. R. Larson, J. N. Rutger, K. A. Young and V. Raboy, "Isolation and Genetic Mapping of a Non-Lethal Rice (Oryza sativa L.) Low Phytic Acid 1 Mutation,” Crop Science, Vol. 40, No. 5, 2000, pp. 1397-1405. http://dx.doi.org/10.2135/cropsci2000.4051397x

[11] V. Raboy, P. F. Gerbasi, K. A. Young, S. D. Stoneberg, S. G. Pickett, A. T. Bauman, P. P. N. Murthy, W. F. Sheridan and D. S. Ertl, "Origin and Seed Phosphate of Maze Low Phytic Acid 1-1 and Low Phytic Acid 2-1," Plant Physiology, Vol. 124, No. 1, 2000, pp. 335-368. http://dx.doi.org/10.1104/pp.124.1.355

[12] J. R. Wilcox, G. S. Premachandra, K. A. Young and V. Raboy, "Isolation of High Seed Inorganic P, Low-Phytate Soybean Mutants," Crop Science, Vol. 40, 2000, pp. 1601-1605. http://dx.doi.org/10.2135/cropsci2000.4061601x

[13] D. S. Ertl, K. A. Young and V. Raboy, "Plant Genetic Approaches to Phosphorus Management in Agricultural Production,” Journal of Environmental Quality, Vol. 27, No. 2, 1998, pp. 299-304. http://dx.doi.org/10.2134/jeq1998.00472425002700020008x

[14] Y. C. Li, D. R. Edoux, T. L. Veum, V. Raboy and D. S. Ertl, "Effects of Low Phytic Acid Corn on Phosphorus Utilization Performance, and Bone Mineralization in Broiler Chicks,” Poultry Science, Vol. 79, 2000, pp. 14441450.

[15] C. H. Fox and M. Eberl, "Phytic Acid (IP6), Novel Broad Spectrum Anti-Neoplastic Agent: A Systematic Review,”
Complementary Therapies in Medicine, Vol. 10, No. 4, 2002, pp. 229-234.

http://dx.doi.org/10.1016/S0965-2299(02)00092-4

[16] D. Oberleas, "Determination of Phytate and Inositol Phosphates,” Methods of Biochemical Analysis, Vol. 20, 1971, pp. 87-101.

http://dx.doi.org/10.1002/9780470110393.ch3

[17] I. A. Vaintraub and N. A. Lapteva, "Colorimetric Determination of Phytate in Unpurified Extracts of Seed and the Products of Their Processing," Analytical Biochemistry, Vol. 175, No. 1, 1988, pp. 227-230. http://dx.doi.org/10.1016/0003-2697(88)90382-X

[18] N. Wang, D. W. Hatcher, R. Toews and E. J. Gawalko, "Influence of Cooking and Dehulling on Nutritional Composition of Several Varieties of Lentils (Lens culinaris)," Food Science and Technology, Vol. 42, No. 4, 2009, pp. 842-848.

[19] B. Campion, F. Sparvoli, E. Doria, G. Tagliabue, I. Galasso, M. Fileppi, R. Bollini and E. Nielson, "Isolation and Characterization of an Lpa (Low Phytic Acid) Mutant in Common Bean (Phaseolus vulgaris L.)," Theoretical and Applied Genetics, Vol. 118, No. 6, 2009, pp. 12111221. http://dx.doi.org/10.1007/s00122-009-0975-8

[20] B. W. Agranoff, "Phosphorylated Derivatives of MyoInositol,” Federation Proceedings, Vol. 45, No. 11, 1986, pp. 2629-2633.

[21] P. Scholz, G. Bergmann and G. W. Mayr, "Methods in Inositide Research,” In: R. F. Irvine, Ed., In Vitro Cellular \& Developmental Biology, Raven Press, Ltd., New York, 1990, pp. 65-82.

[22] V. Raboy, "Myo-Inositon-1, 2, 3, 4, 5, 6-Hexakisphosphate," Phytochemistry, Vol. 64, No. 6, 2003, pp. 10331043. http://dx.doi.org/10.1016/S0031-9422(03)00446-1

[23] V. Raboy and P. Gerbasi, "Genetics of Myo-Inositol Phosphate Synthesis and Accumulation," Subcellular Biochemistry, Vol. 26, 2006, pp. 275-285.

[24] S. T. Safrany, J. J. Caffrey, X. Yang and S. B. Shears, "Diphosphoinositol Polyphosphates: The Final Frontier for Inositide Research?” The Journal of Biological Chemistry, Vol. 380, No. 7-8, 1999, pp. 945-951.

[25] L. A. Hankahi and S. C. West, "Specific Interaction of IP6 with Human Ku70/80, the DNA-Binding Subunit of DNA-PK," The European Molecular Biology Organzation Journal, Vol. 21, No. 8, 2002, pp. 2038-2044. http://dx.doi.org/10.1093/emboj/21.8.2038

[26] A. Saiardi, C. Sciambi, J. M. McCaffery, B. Wendland and S. H. Snyder, "Inositol Pyrophosphate Regulate Endocytic Trafficking," Proceedings of the National Academy of Sciences of the United States of America, Vol. 99, No. 22, 2002, pp. 14206-14211. http://dx.doi.org/10.1073/pnas.212527899

[27] E. Graf, K. L. Empson and J. W. Eaton, "Phytic Acid. A Natural Antioxidant," The Journal of Biological Chemistry, Vol. 262, No. 24, 1987, pp. 11647-11650.

[28] E. Graf and J. W. Eaton, "Antioxidant Functions of Phytic Acid,” Free Radical Biology and Medicine, Vol. 8, 1990, pp. 61-69. http://dx.doi.org/10.1016/0891-5849(90)90146-A

[29] P. Thavarajah, D. Thavarajah and A. Vandenberg, "Low 
Phytic Acid Lentils (Lens culinaris L.) A Potential Solution for Increased Micronutrient Bioavailability,” Journal of Agricultural and Food Chemistry, Vol. 57, No. 19, 2009, pp. 9044-9049. http://dx.doi.org/10.1021/jf901636p

[30] N. R. Reddy and M. D. Pierson, "Isolation and Partial Characterization of Phytic Acid-Rich Particles from Great Northern Beans (Phaseolus vulgaris L.)," Journal of Food Science, Vol. 52, 1987, pp. 109-112. http://dx.doi.org/10.1111/j.1365-2621.1987.tb13983.x

[31] S. B. Elhardallou and A. F. Walker, "Phytic Acid Content of Three Legumes in the Row, Cooked and Fibre Forms," Phytochemical Analysis, Vol. 5, 1994, pp. 243-246. http://dx.doi.org/10.1002/pca.2800050505

[32] J. B. Ohlrogge and T. P. Kerman, "Oxygen-Dependent Aging of Seeds,” Plant Physiology, Vol. 70, No. 3, 1982, pp. 791-794. http://dx.doi.org/10.1104/pp.70.3.791

[33] S. Plammi, "Myoinositol Phosphates: Analysis, Content in Foods and Effects in Nutrition," Lebensmittel-Wissenschaft und-Technologie, Vol. 30, 1997, pp. 633-647.

[34] P. Talamond, S. Doulbeau, I. Rochette, J. P. Guyot and S. Treche, “Anion-Exchange High Performance Liquid Chro- matography with Conductivity Detection for the Analysis of Phytic Acid in Food," Journal of Chromatography A, Vol. 871, No. 1-2, 2000, pp. 7-12. http://dx.doi.org/10.1016/S0021-9673(99)01226-1

[35] E. Skoglund, N. Carlsson and A. Sandberg, "Determination of Isomers of Inositol Mono- to Hexaphosphates in Selected Food and Intestinal Contents Using High Performance Liquid Chromatography," Journal of Agricultural and Food Chemistry, Vol. 45, 1997, pp. 431-436. http://dx.doi.org/10.1021/jf9603238

[36] E. Skoglund, N. Carlsson and A. Sandberg, "High-Performance Chromatographic Separation of Inositol Phosphate Isomers on Strong Anion Exchange Columns,” Journal of Agricultural and Food Chemistry, Vol. 46, 1998, pp. 18771882. http://dx.doi.org/10.1021/jf9709257

[37] J. Lehrfeld, "HPLC Separation and Quantification of Phytic Acid and Some Inositol Phosphates in Foods: Problems and Solutions," Journal of Agricultural and Food Chemistry, Vol. 42, No. 12, 1994, pp. 2726-2731. http://dx.doi.org/10.1021/jf00048a015 